Verkaik, R., Francke, A.L., Meijel, B. van, Spreeuwenberg, P.M.M., Ribbe, M.W., Bensing, J.M. The effects of a nursing guideline on depression in psychogeriatric nursing home residents with dementia. International Journal of Geriatric Psychiatry: 2011, 26(7), 723-732

\begin{tabular}{|l|l|}
\hline Postprint Version & 1.0 \\
\hline Journal website & $\underline{\text { http://onlinelibrary.wiley.com/doi/10.1002/gps.2586/abstract;jsessionid=0151A }}$ \\
\hline CABC52BDE2E35A9B5B924EEA21C.d02t01 \\
\hline Pubmed link & $\underline{\text { http://www.ncbi.nlm.nih.gov/pubmed/21077049 }}$ \\
\hline DOI & $10.1002 /$ gps.2586 \\
\hline
\end{tabular}

This is a NIVEL certified Post Print, more info at http://www.nivel.eu

\title{
The effects of a nursing guideline on depression in psychogeriatric nursing home residents with dementia
}

\author{
RENATE VERKAIK $^{1 \$}$, ANNEKe L. FranCKE ${ }^{1,2^{*},}$, BERNO VAN MEIJEL $^{3,-}$, PETER M.M. SPREEUWENBERG $^{1 \$}$, \\ MIEL W. RIBBE ${ }^{2, \%}$ AND JOZIEN M. BENSING ${ }^{1, \#}$ \\ ${ }^{1}$ NIVEL, Netherlands Institute for Health Services Research, Utrecht, the Netherlands \\ ${ }^{2}$ EMGO Institute/VU University Medical Center, Amsterdam, the Netherlands \\ ${ }^{3}$ INHolland University for Applied Sciences, Amsterdam, the Netherlands Correspondence to: R. Verkaik, E- \\ mail: r.verkaik@nivel.nl \\ \$Researcher. \\ * Research Coordinator. \\ ${ }^{\S}$ Professor in Nursing at the end of life. \\ - Associate Professor in Mental Health Nursing. \\ ${ }^{\%}$ Professor in Nursing Home Medicine. \\ \# Professor in Health Psychology, Director.
}

Objective: To study the effects of introducing a nursing guideline on depression in residents with dementia of psychogeriatric nursing home wards.

Methods: A multi-center controlled clinical trial with randomization at ward level was used to study the effects of the guideline introduction. Nursing teams were trained in applying the guideline to their own residents diagnosed with depression in dementia. Key elements of the nursing guideline are increasing individualized pleasant activities and decreasing unpleasant events. Participating residentswere 97 residents diagnosed with dementia and comorbid depression, from 18 psychogeriatric nursing home wards, in 9 Dutch nursing homes.Measurements took place at pre-test, post-test and follow-up. Primary outcome was severityofdepressionmeasuredwiththeMDS/RAI-DepressionRating Scale(DRS) andtheCornell Scale for Depression in Dementia. Secondary outcome is mood as measured by the FACEobservation scale.

Results: Compliance with the nursing guideline was moderate. Despite this, residents on the experimental wards showed a significant reduction in depression on the DRS. With the Cornell scale a reduction of depression was found as well, although not significantly different from that in the control group. No effects on observed mood were found.

Conclusion: This study shows significant reductions in depression severity by introducing a nursing guideline on psychogeriatric nursing home wards. Better compliance with the guideline could probably enlarge the effects. Some ways to achieve enhanced compliance are: (1) additionally train non-certified nurse assistants, and (2) emphasize necessary conditions for successful introduction of the guideline to nursing team managers. Copyright 2010 John Wiley $\&$ Sons, Ltd. 
Key words: dementia; depression; nursing; effects

\section{INTRODUCTION}

The prevalence rate of depression in Dutch psychogeriatric nursing home residents with dementia has recently been estimated at 19\% (Verkaik et al., 2009; Zuidema et al., 2007). This is comparable to the prevalence rate in the UK (Margallo-Lana et al., 2001) and somewhat lower than the rate of 29\% (Evers et al., 2002) or $26 \%$ (Payne et al., 2002) in the United States. Comorbid depression in patients with dementia has been associated with decreased quality of life (Shin et al., 2005), greater health-care utilization (Kunik et al., 2003) and higher mortality rates (Suh et al., 2005). It is not only residents who are burdened by the depression but also indirectly their close relatives and professional caregivers (Kerkstra and Van Bilsen, 1999; Shin et al., 2005). In 2003 we therefore developed a guideline for nurse assistants (Verkaik et al., 2004; Francke and Verkaik, 2006). In the first phase of the development trajectory a systematic review into the effectiveness of 13 often used psychosocial methods (like validation and reminiscence) was performed (Verkaik et al., 2005). The review concluded that there was evidence, although still limited, that BehaviorTherapy-PleasantEvents as developed and studied by Teri et al. (1997) was effective in reducing depression in community-dwelling people with dementia who attended a day care center of a hospital. BehaviorTherapy-PleasantEvents is based on the Integrative Theory of Depression and the Pleasant Events Schedules developed by Lewinsohn et al. (1985). Figure 1 shows the depression cycle described in the Integrative Theory of Depression. According to this theory an existing depression can be interrupted by breaking into the depression cycle at any point (A to F). The Pleasant Events Schedules aim at breaking into the depression cycle specifically at point $\mathrm{C}$, the point at which depressed individuals experience fewer activities as pleasant, engage in pleasant activities less frequently, and therefore obtain less positive reinforcement than other individuals. The Pleasant Events Schedules aim at increasing pleasant activities and positive interactions with the environment. Besides increasing pleasant events, a second aim of the BehaviorTherapy-PleasantEvents is reducing unpleasant events for people with dementia - the second part of element $\mathrm{C}$ of Lewinsohn's model. For our nursing guideline we adapted the method of Teri et al. (1997) to the context of residential care provided by certified nurse assistants (CNAs) in collaboration with other caregivers. For the introduction of the guideline into the psychogeriatric nursing home wards a specific training program was developed in which the nursing teams learned how to apply the guideline to their own residents. The objective of this article is to study the effects of the introduction of the nursing guideline on depression in demented nursing home residents of psychogeriatric wards.

\section{[FIGURE 1]}

\section{METHODS}

\section{Design}

The study is a multi-center controlled intervention on 18 psychogeriatric wards of 9 nursing homes, with randomization at ward level. Each nursing home provided an experimental and a control ward. On the nine experimental wards the nursing guideline was introduced. On the nine control wards usual care continued. The introduction period lasted 11 weeks per ward. There were three measuring moments:

(1) pre-test (in the 2 weeks just before the guideline introduction);

(2) post-test (in the 2 weeks after the intervention period);

(3) follow-up (10-12 weeks after the intervention period).

Data-collection took place between November 2005 and May 2007. The study was approved by the Dutch Central Committee on Research involving Human Subjects (CCMO).

\section{Setting}

The participating nursing homes had applied in reaction to an invitation letter that was sent to 109 nursing homes in the central and western part of the Netherlands. Fifteen nursing homes applied that met the 
Verkaik, R., Francke, A.L., Meijel, B. van, Spreeuwenberg, P.M.M., Ribbe, M.W., Bensing, J.M. The effects of a nursing guideline on depression in psychogeriatric nursing home residents with dementia. International Journal of Geriatric Psychiatry: 2011, 26(7), 723-732

eligibility criteria. The participating homes were the first nine which applied and met the following eligibility criteria:

(1) A minimum of two nursing teams working at two different but comparable psychogeriatric wards;

(2) The nursing teams did not work on each other's wards during the trial;

(3) The nursing teams were not yet applying any systematic methods that are comparable to the guideline;

(4) No reorganizations or other interventions had been planned for the wards that might interfere with the introduction of the guideline.

\section{Participants}

CNAs. In the current study, in principle, complete nursing teams participate. Exclusion criteria for individual caregivers were: (1) not certified or not registered; (2) employed for less than $20 \mathrm{~h}$ per week.

\section{Residents.}

Initially all residents of the 18 participating wards $(n=598)$ were screened for dementia with comorbid depression in two steps, as advised by Logsdon and Teri (1995). As a first step the nursing team manager or another nurse (assistant) were trained and screened all residents of the participating wards for possible depression with the Dutch proxy version of the Geriatric Depression Scale-15 (Yesavage et al., 1982-1983; D'Ath et al., 1994), called Geriatric Depression Scale-15-caregiver. All residents with a score of 4 or higher were selected as possibly depressed (D'Ath et al., 1994), and entered the second step of the screening process. As a second step either the nursing home physician or psychologist determined by observing and interviewing the patient, consulting other caregivers and by studying the medical file, whether a resident met the following inclusion criteria:

(1) Diagnosis of dementia (all types) (APA, 1996);

(2) Severity of dementia from "age associated memory impairment" to "moderately severe dementia" (Global Deterioration Scale stages 2-6: Reisberg et al., 1982). Residents with severe dementia (Global Deterioration Scale stage 7) were excluded from the study because the intervention was aimed at residents who were still able to verbally communicate;

(3) Diagnosed with depression in dementia according to the Provisional Diagnostic Criteria for depression of Alzheimer's Disease (PDC-dAD: Olin et al., 2002). Because the diagnosis of dementia was established but not the type (see inclusion criterion 1), criterion B of the PDC-dAD "All criteria are met for dementia of the Alzheimer type" was not considered. For all residents that met the three inclusion criteria, their legal guardians were asked to give informed consent for study participation.

\section{Conditions}

In each nursing home the two participating wards were randomly assigned to one of two conditions (1) "usual care" (no intervention), or (2) "introduction of the guideline" in addition to usual care (intervention). Allocation of the two wards in each nursing home to one of the two conditions was performed by an independent, blinded colleague at the NIVEL institute drawing lots from a sealed envelop. Each ward of a nursing home that was drawn first was assigned to the experimental condition. Figure 2 describes the content of the guideline introduction. The CNAs of the control wards were kept blind for the content of the guideline. CNAs of the experimental wards signed an agreement that they would not talk to the caregivers of the control wards about the guideline and the content of the training they received. In the same contract they agreed not to work on each other's wards during the period the experiment took place.

\section{[FIGURE 2]}

\section{Data collection}

There were four different ways of collecting data:

(1) an interview with the primary CNA of the resident (Instruments: Cornell, DRS, CPS, CDS);

(2) observation of morning care (Instrument: FACE);

(3) observation during residence in the living room (Instrument: FACE);

(4) collection of medical data from nursing home pharmacies. 
Verkaik, R., Francke, A.L., Meijel, B. van, Spreeuwenberg, P.M.M., Ribbe, M.W., Bensing, J.M. The effects of a nursing guideline on depression in psychogeriatric nursing home residents with dementia. International Journal of Geriatric Psychiatry: 2011, 26(7), 723-732

During the interview with the primary CNA of the resident background information of the resident was also collected. The interviews and observations were carried out by blinded trained research assistants, who were not informed about the research questions and conditions. In total 15 different research assistants conducted the interviews and observations. Most research assistants followed a Master program in psychology.

\section{Outcome measures}

\section{Primary outcome.}

The primary outcome is depression severity. Instruments used to assess depression severity are the Cornell Scale for Depression in Dementia (Alexopoulos et al., 1988) (Dutch version) and the Depression Rating Scale (DRS) of the Minimum Data Set (MDS) of the Resident Assessment Instrument (Burrows et al., 2000) (Dutch version). The Cornell scale contains nineteen depressive symptoms in five domains (Moodrelated signs, Behavioral Disturbance, Physical Signs, Cyclic Functions, Ideational Disturbance). Each item is rated on a scale from "absent," "mild," to "severe." The Cornell scale has a high inter-rater reliability (weighted Kappa $\alpha=0.67$ ) and internal consistency (Cronbach's $=0.84$ ) and was specifically developed to assess depression in people with dementia (Alexopoulos et al., 1988). The DRS is an observational scale, based on seven items (negative statements, persistent anger, expressions of what seem to be unrealistic fears, repetitive health complaints, repetitive anxious complaints/ concerns, sad/pained/worried facial expressions, crying/ tearfulness) which are rated on a scale from "indicator not exhibited in last 30 days," "indicator of this type exhibited up to 5 days a week," to "indicator of this type exhibited daily or almost daily." The internal consistency of the DRS has been established at 0.71 (Cronbach's $\alpha$ ) and the sensitivity against a formal diagnosis of depression at $91 \%$. The scale was specifically developed to assess depression in the frail nursing home population based on CNA observations (Burrows et al., 2000).

\section{Secondary outcome.}

As secondary outcome to the severity of depression, the variable "mood" is assessed. Observed mood concerns the emotional consequences of depression (see part F of Lewinsohn's Integrative Theory of Depression), and is assessed with the instrument FACE that was proved to be reliable in a severely demented and institutionalized population (Volicer et al., 1999). FACE consists of three face diagrams with different mouth shapes. Mood is rated as if smile pre-dominates; if the expression is neutral; if frown predominates. Scores range from 1 (happy) to 3 (sad). The Intraclass Correlation Coefficient (ICC) for the average FACE measures during morning care was 0.88 (95\% CI 0.53-0.99) based on the observations of eight research assistants.

\section{Control measures.}

Control measures (covariates) are gender, marital status, duration of residence in the nursing home, care dependency as measured with the Care Dependency Scale (Dijkstra et al., 1996, 1999), cognitive impairment as measured with the Cognitive Performance Scale of the Resident Assessment Instrument (Morris et al., 1994), and medication use (antidepressants, antipsychotics, benzodiazepines and ACEinhibitor/ß-blockers) during the study period as reported by the nursing homes' pharmacists. In the literature these variables are mentioned as (possible) confounders for the occurrence of depression in people with dementia and/or nursing home residents (Dhondt et al., 2002; Gruber-Baldini et al., 2005; Holtzer et al., 2005; Smalbrugge et al., 2006; Grünblatt et al., 2008).

\section{Sample size}

A two-sided alpha of 5\% and $80 \%$ power was used to calculate the sample size of nursing home residents. Based on the study of Teri et al. (1997) the effect size for measuring differences in depression severity was cautiously estimated as 0.7 on the Cornell scale. This means that with $80 \%$ power a sample of 33 nursing home residents in both groups would be needed (Cohen, 1988).

\section{Statistical methods}

Multilevel Repeated Measures Analysis was used for analyzing the data, using MLwiN-software (Rasbash et al., 2000). Four different levels of analysis were distinguished in the model: (1) measurement; (2) resident; (3) ward; (4) nursing home. The multi-level model takes into account all available data yielding outcome measures in an adequate way: the paired samples of residents that have all three or two of the tests (pre-test and post-test) as well as the unpaired pre-measurement data of those residents that only have pre- 
test data. The correlated paired measurements are controlled for by modeling the covariance between the measurements at the residents' level (Bryk and Raudenbusch, 1992; Goldstein, 1995). The multi-level model cannot be applied to residents for whom not all covariate data are complete. These cases $(n=3)$ were excluded from the analyses. Data of the residents with complete covariate data $(n=97)$ were analyzed using the intention-to-treat principle: all participants were analyzed according to group assignment. For all outcome measures on pre-test, post-test and follow-up adjusted estimated means and standard errors were calculated for the experimental and control group. Adjusted estimated means are the average scores corrected for the scores on the baseline measurement and other covariates. To compare differences in trends from pre-test to follow-up (linear or quadratic) between the experimental and the control group Chi squares $(\mathrm{df}=1)$ were calculated. Trends were considered to differ significantly if Chi-square _3.84 (p_0.05). Linear and quadratic differences were both calculated because it is possible that the effects of the guideline introduction are larger immediately after the intervention (post-test) than at follow-up.

\section{[FIGURE 3] [TABLE 1]}

\section{RESULTS}

\section{Selection of participants}

As described, the selection of participants took place in two steps. Figure 3 presents the study flow diagram. As a first step all residents $(\mathrm{n}=598)$ of the 18 participating wards were screened by the team manager or certified nurse (assistant) for possible depression with the Geriatric-Depression-Scale-15caregiver (302 residents on the experimental wards and 296 on the control wards). From the screening 313 residents showed signs of possible depression (GDS-15-caregiver score_4). Analyses show that the percentage of residents with possible depression did not significantly differ between the experimental and control group. From the 313 residents with possible depression 20 deceased and 2 were transferred before they could enter the second step of the diagnostic procedure in which nursing home physicians or psychologists established the diagnosis of dementia, depression in dementia and dementia severity. Of the 291 residents that did enter the second step of the diagnostic procedure 100 fulfilled the inclusion criteria: 65 in the experimental group and 35 in the control group. In the other 191 case 110 did not meet the inclusion criteria: 10 had no dementia, 78 had no depression in dementia and 22 were in the last stage of dementia. Forty-one residents could not be included in the trial because the physicians/ psychologists had no time for the diagnostic procedure. In 38 cases the reason for exclusion was unknown. The analysis of this article includes data of 62 residents in the experimental group and 35 residents in the control group $(n=97)$. Data of three residents in the experimental group could not be used because of missing data about their psychoactive medication use. Background characteristics of the 97 residents are presented in Table 1. Analyses show that the experimental and control group do not significantly differ on any of the background characteristics, and on the mean number of PDC-dAD depression symptoms (p_0.05). Fifteen residents were lost to post-test due to transfer or death (six experimental; seven control) and eight more residents in the experimental group were lost to the 10- to 12-week follow-up due to death, while 0 in the control group. The collected data of these 23 residents that were lost after pre-test could still be used in the multi-level analyses according to the intentiontotreat principle. Analyses show no differences in background characteristics between residents who were involved until the end of the study and residents who were not ( p_0.05).

\section{Success of the guideline introduction}

For 39 of the 65 residents (60\%) who participated in the experimental group a Pleasant-Activities-Plan was developed and inserted into the residents care file. For the other 26 participating residents a PleasantActivities-Plan was also developed but not entered into the files. This provides an indication of the success of the guideline introduction. Analyses for another paper showed that on three wards the guideline introduction was successful, on four it was moderately successful and on two not successful. On all six moderately and not-successful wards CNAs stated that the actual use of the guideline was inhibited by reorganizations, too few personnel, other training courses at the time of the guideline introduction or no actual support from the team manager and/or higher management. In addition, on all nine wards CNAs 
Verkaik, R., Francke, A.L., Meijel, B. van, Spreeuwenberg, P.M.M., Ribbe, M.W., Bensing, J.M. The effects of a nursing guideline on depression in psychogeriatric nursing home residents with dementia. International Journal of Geriatric Psychiatry: 2011, 26(7), 723-732

stated that involving the non- CNAs and nursing helpers in the guideline introduction would likely have improved the guideline application.

\section{Primary outcome: depression severity}

Table 2 provides the adjusted estimated means and standard errors for the experimental and control group for all outcome measures on pre-test, post-test, and follow-up. The table also shows Chi-square values that indicate if trends in the experimental and control groups differ significantly ( $\left.\mathrm{p}_{-} 0.05\right)$ in a linear or quadratic way. A significant treatment effect was obtained for depression on the MDS/RAI-DRS. In the experimental group depression severity reduced from $4.56(0.35)$ to $3.91(0.35)$ at post-test to 3.79 ( 0.38$)$ at followup. In the control group depression severity at pre-test is 3.84 (_0.52), at post-test rises to 4.61 ( 0.57$)$ and than decreases to follow-up to 4.07 ( 0.61$)$. The differences are quadratic because of the rise and fall of depression severity in the control group. The treatment effect was not significant on the Cornell scale, although the trend in the experimental group shows a reduction of depression from 11.42 ( 0.62$)$ at baseline to $10.31(0.57)$ at post-test, to $9.96(0.66)$ at follow-up. The trend in the control group first remains at the same level from pre-test to post-test (11.48_0.90 to 11.46_1.12) and then drops to 9.93 (_1.18).

\section{[TABLE 2]}

\section{Secondary Outcome: observed mood}

No significant effect of the guideline introduction was found on observed mood. For both observations during morning care and observations during residence in the living room the mean mood scores remain stable in both the experimental and control groups, from pretest to follow-up.

\section{DISCUSSION}

\section{Effects on depression}

This article shows that introducing the nursing guideline on depression for psychogeriatric nursing home residents reduces depression severity as measured with the MDS/RAI-DRS. The reduction of depression on the DRS is, however, not statistically confirmed by the Cornell Scale for Depression in Dementia, since on the Cornell Scale only a non-significant reduction of depression was established. Kurlowicz et al. (2002) may offer a possible explanation for the finding that we do find significant effects on the DRS, while the decrease in depression on the Cornell is not significant. In their psychometric evaluation of the Cornell scale in a nursing home population Kurlowicz et al. conclude that " ....in frail, institutionalized older adults with high rates of dementia, medical illness, and functional disability, depression measurements that are less dependent on items highly sensitive to comorbid conditions and not necessarily associated with depression may be more appropriate.' Examples of items sensitive to comorbid conditions are item 7 "multiple physical complaints" and item 10 "weight loss." The DRS, having been specifically developed for the frail nursing home population and less dependent on physical conditions, could be a good example of such a more appropriate instrument. Two examples of items in the DRS are "persistent anger with self and others" and "repetitive anxious complaints/concerns." The lack of effects on the variable observed mood may be related to low sensitivity of the FACE-scale in our demented and depressed population. The three-point scale allowed little variation in observed mood as assessed. Analyses showed that observation scores centered around the "neutral"'- category and were distributed with smaller tails than in a normal distribution.

\section{Effect size}

The effect size is a measure that can be used to determine the clinical relevance of an effect (Cohen, 2008). The size of the effect of the guideline introduction on depression severity is moderate, with a standardized difference of +1.1 at pre-test and a standardized difference of -0.4 at follow-up (Cohen, 1988). The moderate effect may be related to the limited compliance with the guideline for wards on which the guideline introduction had been less successful. In sub-group analyses we found indications of this. We found that the mean reduction in depression severity as measured with the DRS from post-test to follow-up was larger on the successful wards than on the moderately and non-successful wards. Differences were, however, not statistically significant ( $\mathrm{p} \geq 0.5$ ), probably because of the small sizes of the subgroups. 
Verkaik, R., Francke, A.L., Meijel, B. van, Spreeuwenberg, P.M.M., Ribbe, M.W., Bensing, J.M. The effects of a nursing guideline on depression in psychogeriatric nursing home residents with dementia. International Journal of Geriatric Psychiatry: 2011, 26(7), 723-732

\section{Comparison with BehaviorTherapy-PleasantEvents}

The study by Teri et al. (1997) on the effects of BehaviorTherapy-PleasantEvents showed large, significant, clinically relevant reductions in depression severity in people with comorbid depression and dementia. Why were the effects that we found smaller? One important difference seems to be that in Teri's study the people with dementia were still living at home with a close relative who took care for them all the time. The relative learned how to develop and apply the Pleasant- Events-Plan from a day-care center geriatrician. In our study the Pleasant-Event-Plans were developed and applied by CNAs. CNAs had less support with the development of the plans and knew the residents less well than the relatives did. Furthermore, CNAs had to communicate and coordinate application of the plans between themselves and other disciplines. Communication of the method to non-CNAs and nursing helpers proved to be problematic, because they were not involved in the training, although they delivered a substantial amount of the residents' daily care.

\section{Study limitations}

The design of the current study has some limitations. Firstly, the randomization of the participating residents was only possible at ward level. In addition, because the CNAs on the control wards had to make the diagnosis of depression themselves, they may have adapted their care at the moment this diagnosis was established, for example, by giving more attention to the residents diagnosed with depression. Changes in attitude of the CNAs could not be controlled for. We also have no insight into the possible influence of the fact that CNAs provided the information on which the DRS and Cornell were scored. Secondly, the participating nursing homes themselves applied for participation. Possibly they already had a more positive attitude towards the method than an average nursing home. This could affect the generalizability of the results. With respect to the international generalizability we know that in most other countries the role and educational level of CNAs on psychogeriatric wards is somewhat different than in the Netherlands. In the United States, for example, CNAs are not trained in developing care plans. In these cases the division of tasks in the guideline could be rearranged according to the specific situation. Licensed Practical Nurses (LPNs) could, for example, take over the development of the Pleasant-Activities-Plans, while CNAs conduct them.

\section{CONCLUSION}

The current study shows that statistically significant reductions in depression severity can be obtained with the introduction of the nursing guideline on comorbid depression in dementia on psychogeriatric nursing home wards. Effects could probably be enlarged if non-CNAs and nursing helpers are also trained, and managers pay more attention to the necessary conditions for successful introduction.

\section{Conflict of interest}

None declared

\section{Acknowledgements}

This study was funded by ZonMw, the Netherlands organization for health research and development (project nr. 5401.0001)

\section{REFERENCES}

Alexopoulos GS, Abrams RC, Young RC, et al. 1988. Cornell scale for depression in dementia. Biol Psychiatry 23: 271-284.

American Psychiatric Association. 1996. DSM-IV Patie"ntenzorg: Diagnostiek en Classificatie van Psychische Stoornissen voor de Geneeskunde. [Diagnostic and Statistical Manual of Mental Disorders, 4th edn., primary care]. Swets \& Zeitlinger: Lisse.

Bryk AS, Raudenbusch SW. 1992. Hierarchical Linear Models: Applications and Datamanagemnt Methods. Sage Publications: Newbury Park.

Burrows AB, Morris JN, Simon SE, et al. 2000. Development of a minimum data set-based depression rating scale for use in nursing homes. Age Aging 29: 165-172.

Cohen J. 2008. A power primer. Psycholog Bulletin 112: 155-159.

Cohen J. 1988. Statistical Power Analysis for the Behavioral Sciences, 2nd edn. Lawrence Erlbaum Association, Inc.: Hillsdale, New Jersey. D'Ath P, Katona P, Mullan E, et al. 1994. Screening, detection and management of depression in elderly primary care attenders. I: the acceptability and performance of 
Verkaik, R., Francke, A.L., Meijel, B. van, Spreeuwenberg, P.M.M., Ribbe, M.W., Bensing, J.M. The effects of a nursing guideline on depression in psychogeriatric nursing home residents with dementia. International Journal of Geriatric Psychiatry: 2011, 26(7), 723-732

the 15 item Geriatric Depression Scale (GDS15) and the development of short versions. Fam Pract 11: 260-266.

Dhondt TD, Beekman AT, Deeg DJ, Van Tilburg W. 2002. Iatrogenic depression in the elderly. Results from a community based study in the Netherlands. Soc Psychiatry Psychiatr Epidemiol 37: 393-398.

Dijkstra A, Buist G, Dassen T. 1996. Nursing care dependency. Development of an assessment scale for demented and mentally handicapped patients. Scan J Caring Sci 10: 137-143.

Dijkstra A, Buist G, Moorer P, et al. 1999. Construct validity of the nursing care dependency scale. J Clin Nurs 8: 330-388.

Evers MM, Samuels SC, Lantz M, et al. 2002. The prevalence, diagnosis and treatment of depression in dementia patients in chronic care facilities in the last six months of life. Int J Geriatr Psychiatry 17: 464472.

Francke AL, Verkaik R. 2006. Begeleiding van mensen met dementie die depressief of apathisch zijn: de ontwikkeling en evaluatie van twee evidence based richtlijnen voor verzorgenden. [Supporting people with dementia with comorbid depression or apathy: development and evaluation of two evidence based nursing guidelines]. Verpleegkunde 21: 53-61.

Goldstein H. 1995. Multilevel Statistical Models. Halsted Press: New York.

Gruber-Baldini AL, Zimmerman S, Boustani M, et al. 2005. Characteristics associated with depression in long-term care residents with dementia.

Gerontologist 45 (Spec No. 1): 50-55.

Grünblatt E, Zehetmayer S, Bartl J, et al. 2008. Genetic risk factors and markers for Alzheimer's disease and/or depression in the VITA study. J

Psychiatr Res 43: 298-308.

Holtzer R, Scarmeas N, Wegesin DJ, et al. 2005. Depressive symptoms in Alzheimer's disease: natural course and temporal relation to function and

cognitive status. J Am Geriatr Soc 53: 2083-2089.

Kerkstra A, Van Bilsen PMA. 1999. Omgaan met Dementerende Bewoners voor Verzorgenden in Het Verpleeghuis [How Caregivers in Nursing Homes Deal With Dementia Patients]. NIVEL: Utrecht.

Kunik ME, Snow AL, Molinari VA, et al. 2003. Health care utilization in dementia patients with psychiatric comorbidity. Gerontologist 43: 86- 91.

Kurlowicz LH, Evans LK, Strumpf NE, et al. 2002. A psychometric evaluation of the Cornell Scale for Depression in Dementia in a frail, nursing

home population. Am J Geriatr Psychiatry 10: 600-608.

Lewinsohn PM, Hoberman H, Teri L, et al. 1985. An integrative theory of depression. In Theoretical Issues in Behaviour Therapy. Reiss S, Bootzin R (eds). Academic Press: New York; 331-359.

Logsdon RG, Teri L. 1995. Depression in Alzheimer's disease patients:caregivers as surrogate reporters. J Am Geriatr Soc 43: 150-155.

Margallo-Lana M, Swann A, O'Brien J, et al. 2001. Prevalence and pharmacological management of behavioural and psychological symptoms amongst dementia sufferers living in care environments. Int J Geriatr Psychiatry 16: 39-44.

Morris JN, Fries BE, Mehr DR, et al. 1994. MDS Cognitive Performance Scale. J Gerontol 49: M174-M182. Olin JT, Schneider LS, Katz IR, et al. 2002. Provisional diagnostic criteria for depression of Alzheimer disease. Am J Geriatr Psychiatry 10: 125-128.

Payne JL, Sheppard JM, Steinberg M, et al. 2002. Incidence, prevalence, and outcomes of depression in residents of a long-term care facility with

dementia. J Geriatr Psychiatry 17: 247-253.

Rasbash J, Browne W, Healy M. 2000. MlwiN (Version 1.10). Multilevel models Project Institute of Education: London.

Reisberg B, Ferris SH, de Leon MJ, et al. 1982. The Global Deterioration Scale for assessment of primary degenerative dementia. Am J Psychiatry

139: 1136-1139.

Shin IS, Carter M, Masterman D, et al. 2005. Neuropsychiatric symptoms nd quality of life in Alzheimer disease. Am J Geriatr Psychiatry 13: 69-474.

Smalbrugge M, Jongenelis L, Pot AM, et al. 2006. Incidence and outcome of epressive symptoms in nursing home patients in the Netherlands. Am J eriatr Psychiatry 14: 1069-1076.

Suh GH, Kil Yeon B, Shah A, Lee JY. 2005. Mortality in Alzheimer's disease: a commparative prospective Korean study in the community and nursing homes. Int J Geriatr Psychiatry 20: 26-34.

Teri L, Logsdon RG, Uomoto J, McCurry SM. 1997. Behavioral treatment of depression in dementia patients: a controlled clinical trial. J Gerontol B Psychol Sci Soc Sci 52: 159-166. 
Verkaik, R., Francke, A.L., Meijel, B. van, Spreeuwenberg, P.M.M., Ribbe, M.W., Bensing, J.M. The effects of a nursing guideline on depression in psychogeriatric nursing home residents with dementia. International Journal of Geriatric Psychiatry: 2011, 26(7), 723-732

Verkaik R, Francke AL, van Meijel B, Spreeuwenberg P, Ribbe MW, Bensing JM. 2009. Comorbid depression in dementia on psychogeriatric nursing home words: which symptoms are prominent? Am J Geriatr Psychiatry 17: 565-573.

Verkaik R, Francke AL, Van Delden D. 2004. Het Begeleiden van Mensen met Dementie Die Depressief Zijn. Richtlijn voor Verzorgenden [Supporting People With Dementia and Comorbid Depression. A Nursing Guideline]. NIVEL: Utrecht.

Verkaik R, Van Weert JCM, Francke AL. 2005. The effects of psychosocial methods on depressed, aggressive and apathetic behaviors of people with dementia: a systematic review. Int J Geriatr Psychiatry 20: 301-314.

Volicer L, Camberg L, Hurley AC, et al. 1999. Dimensions of decreased psychological well-being in advanced dementia. Alzheimer Dis Assoc Disord 13: 192-201.

Yesavage JA, Brink TL, Rose TL, et al. 1982-1983. Development and validation of a geriatric depression screening scale: a preliminary report.

J Psychiatr Res 17: 37-49.

Zuidema SU, Derksen E, Verhey FRJ, et al. 2007. Prevalence of neuropsychiatric symptoms in a large sample of Dutch nursing home patients

with dementia. Int J Geriatr Psychiatry 22: 632-638.

\section{TABLES AND FIGURES}

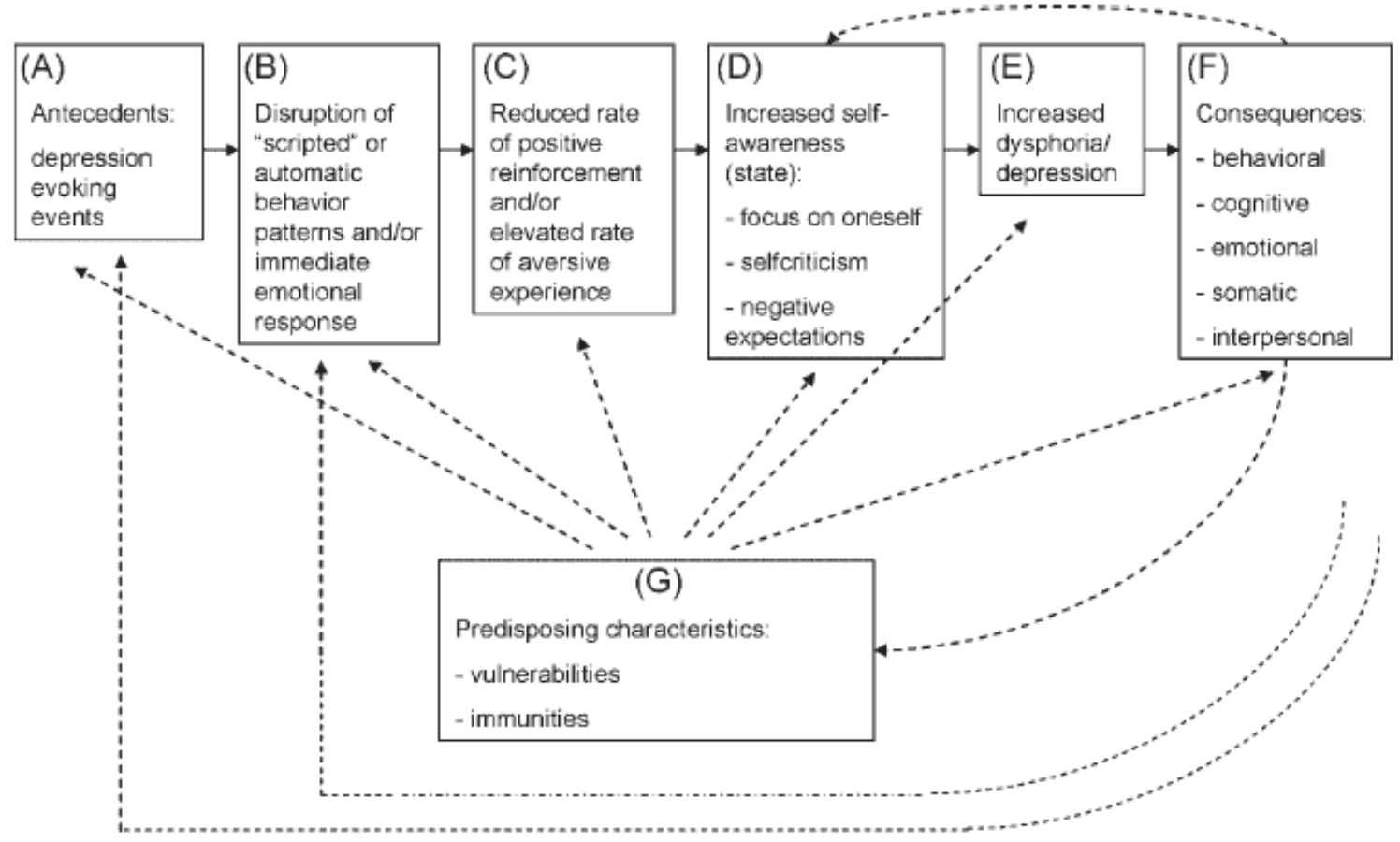

Figure 1 Integrative Theory of Depression (Lewinsohn et al., 1985). 
Verkaik, R., Francke, A.L., Meijel, B. van, Spreeuwenberg, P.M.M., Ribbe, M.W., Bensing, J.M. The effects of a nursing guideline on depression in psychogeriatric nursing home residents with dementia. International Journal of Geriatric Psychiatry: 2011, 26(7), 723-732

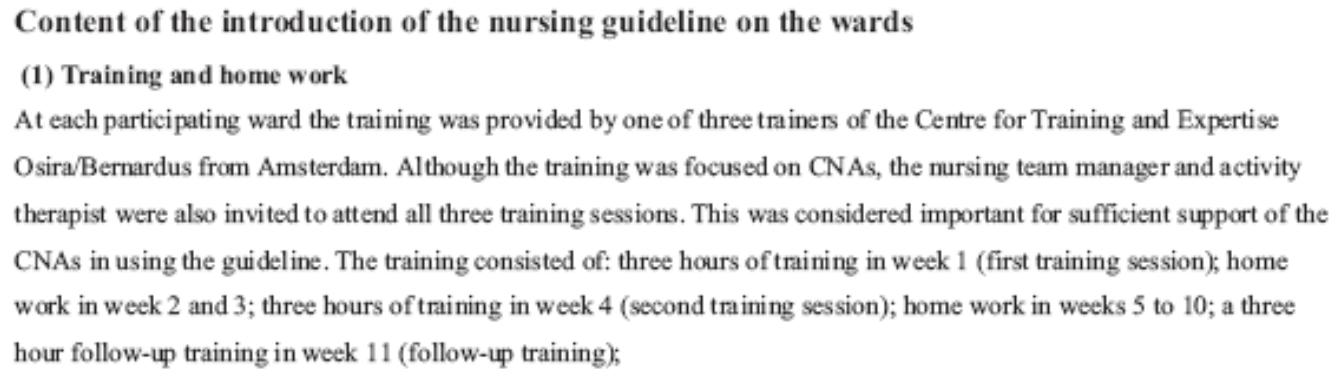

As a first step, data about the life history, personality and preferred and disliked activities were collected from the resident and his or her family. Also information was gathered about present depressive symptoms and the contexts in which these occur. Based on the collected information, the Pleasant-Activities-Plans had to contain written information on depression symptoms and the purposes, planning and evaluation of individualized and tailor-made pleasant activities. Activities in the plan could be conducted by CNAs themselves during regular care (e.g. play preferred music or make jokes during moming care) or during additional care (e.g. go outside into the garden). Activities could also be performed by activity therapists or relatives of the resident (e.g. take the resident to a riding school if he loves horses or to the local pub), but the CNAs are responsible for developing, facilitating and evaluating the activities.

$2^{\text {nd }}$ and follow-1p training sessions

In the second training session the formulated Pleasant-Activities-Plans were discussed in the group. After the necessary adaptations were made, the plans were integrated into daily care and evaluated as described in the plan. In the follow-up training the experiences of the CNAs were discussed for each participating resident and plans were made for further introduction of the guideline onto the ward.

\section{(2) Promotion group}

A "promotion group" consisting of the nursing team manager, activity therapist and two CNAs was installed, with a view to encouraging and supporting the team in following the guideline. This group could consult the trainer between weeks 1 and 11 .

Figure 2 Content of the guideline introduction. 
Verkaik, R., Francke, A.L., Meijel, B. van, Spreeuwenberg, P.M.M., Ribbe, M.W., Bensing, J.M. The effects of a nursing guideline on depression in psychogeriatric nursing home residents with dementia. International Journal of Geriatric Psychiatry: 2011, 26(7), 723-732

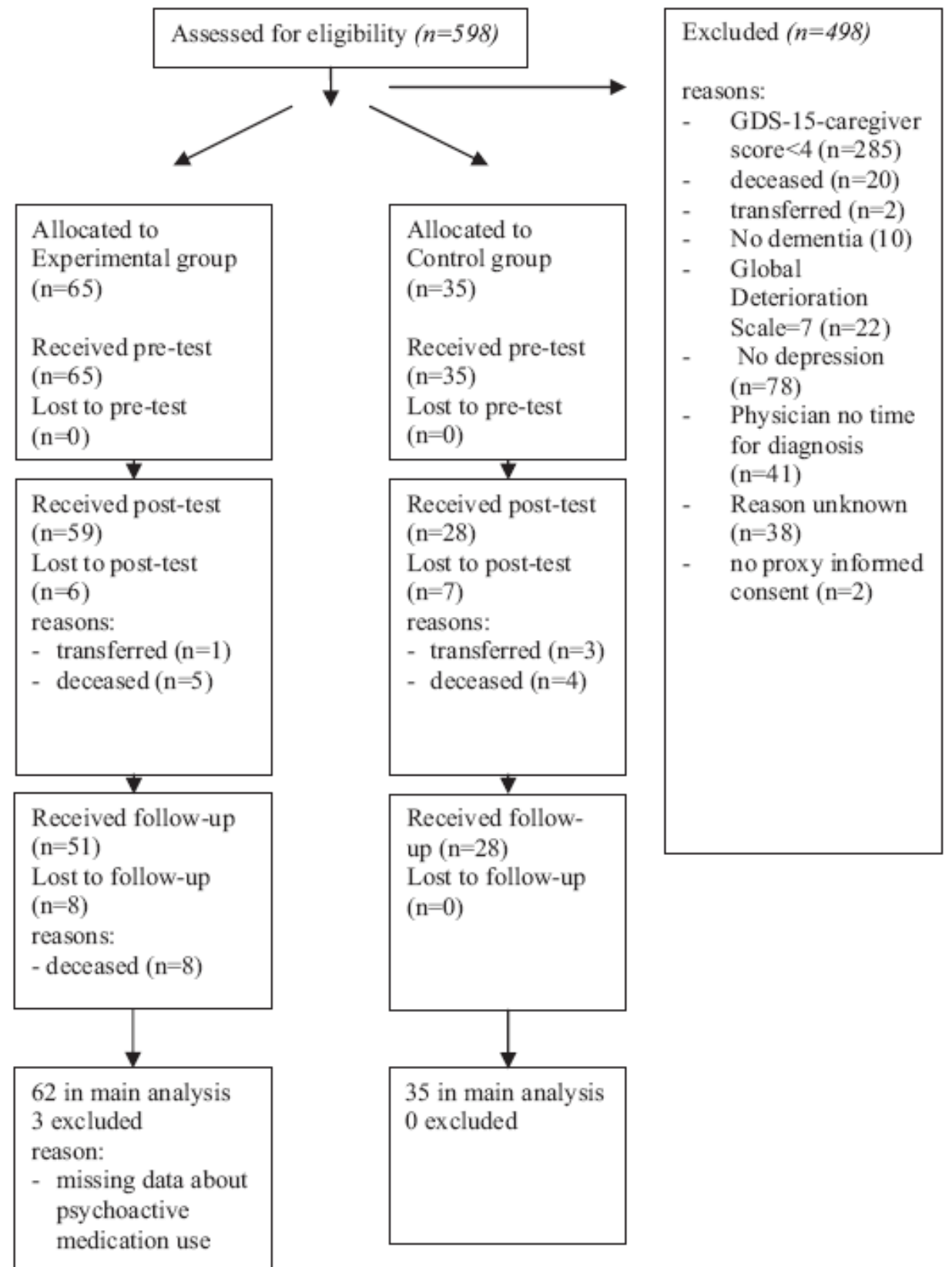

Figure 3 Participant flow. 
Verkaik, R., Francke, A.L., Meijel, B. van, Spreeuwenberg, P.M.M., Ribbe, M.W., Bensing, J.M. The effects of a nursing guideline on depression in psychogeriatric nursing home residents with dementia. International Journal of Geriatric Psychiatry: 2011, 26(7), 723-732

Table 1 Participant background characteristics $(n=97)$

\begin{tabular}{|c|c|c|}
\hline & $\begin{array}{c}\text { Experimental } \\
\text { group } \\
(n=62)\end{array}$ & $\begin{array}{l}\text { Control } \\
\text { group } \\
(n=35)\end{array}$ \\
\hline Age, years (mean $\pm S D$ ) & $83.4 \pm 7.2$ & $84.1 \pm 7.1$ \\
\hline Range & $62-99$ & $66-96$ \\
\hline Sex male, $n(\%)$ & $10(16.1)$ & $7(20)$ \\
\hline \multicolumn{3}{|l|}{ Marital status } \\
\hline Married, $n(\%)$ & $11(17.7)$ & $9(25.7)$ \\
\hline Widow/widower, $n(\%)$ & $46(74.2)$ & $26(74.3)$ \\
\hline Divorced, $n(\%)$ & $3(4.8)$ & $0(0)$ \\
\hline Unmarried, $n(\%)$ & $2(3.2)$ & $0(0)$ \\
\hline \multicolumn{3}{|l|}{ Duration of institutionalization } \\
\hline$<3$ months, $n(\%)$ & $1(1.6)$ & $2(5.7)$ \\
\hline 3 months-1 year, $n(\%)$ & $14(22.6)$ & 8 (22.9) \\
\hline $1-3$ years, $n(\%)$ & $31(50.0)$ & $12(34.3)$ \\
\hline$>3$ years, $n(\%)$ & $16(25.8)$ & $13(37.1)$ \\
\hline \multicolumn{3}{|l|}{ Global Deterioration } \\
\hline \multicolumn{3}{|l|}{ Scale (GDS) } \\
\hline GDS $2, n(\%)$ & $2(3.2)$ & $1(2.9)$ \\
\hline GDS $3, n(\%)$ & $1(1.6)$ & $3(8.6)$ \\
\hline GDS $4, n(\%)$ & $7(11.3)$ & $1(2.9)$ \\
\hline GDS $5, n(\%)$ & $23(37.1)$ & $8(22.9)$ \\
\hline GDS $6, n(\%)$ & $22(35.5)$ & $18(51.4)$ \\
\hline Missing & $7(11.3)$ & 4 (11.3) \\
\hline \multicolumn{3}{|l|}{ Psychoactive medication use } \\
\hline Antidepressant drugs, $n$ (\%) & $28(45.2)$ & $9(25.7)$ \\
\hline Antipsychotic drugs, $n(\%)$ & $27(43.5)$ & $22(62.9)$ \\
\hline Benzodiazepines, $n(\%)$ & $25(40.3)$ & $13(37.1)$ \\
\hline ACE-inhibitors/beta- & $6(9.7)$ & $3(8.6)$ \\
\hline blockers (\%) & & \\
\hline
\end{tabular}


Verkaik, R., Francke, A.L., Meijel, B. van, Spreeuwenberg, P.M.M., Ribbe, M.W., Bensing, J.M. The effects of a nursing guideline on depression in psychogeriatric nursing home residents with dementia. International Journal of Geriatric Psychiatry: 2011, 26(7), 723-732

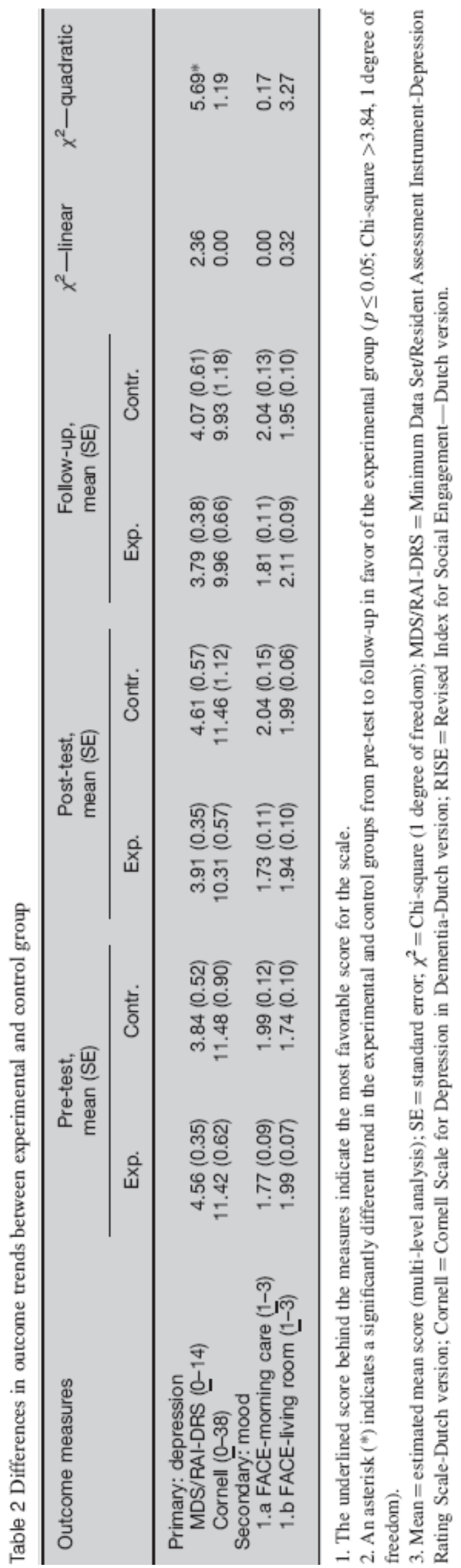

